\title{
ANT Perspective of Healthcare Big Data for Service Delivery in South Africa
}

\author{
Tiko Iyamu, Cape Peninsula University of Technology, Cape Town, South Africa \\ iD https://orcid.org/0000-0002-4949-094X
}

Sibulela Mgudlwa, Cape Peninsula University of Technology, South Africa

\begin{abstract}
In South Africa, there has been for many years challenges in how healthcare big data are accessed, used, and managed by facilities, particularly the small health facilities. The challenges arise from inaccuracy and inconsistency of patients' data and have impact on diagnoses, medications, and treatments, which consequently contributes to fatalities in South Africa, particularly in the rural areas of the country. The problem of inaccuracy and inconsistency of patients' data is often caused by lack of or poor analysis (or analytics) of data. Thus, the objective of this research was to understand the factors that influence the use and management of patients' big data for healthcare service delivery. The qualitative methods were applied, and a South African healthcare facility was used as a case in the study. Actor network theory (ANT) was employed as a lens to guide the analysis of the qualitative data. Based on the findings from the analysis, a model was developed, which is intended to guide analytics of big data for healthcare purposes, towards improving service delivery in the country.
\end{abstract}

\section{KEYWORDS}

Actor-Network Theory, Big Data, Healthcare, South Africa

\section{INTRODUCTION}

Due to the essentiality of healthcare, delivery of quality service is always crucial (Cresswell, Worth \& Sheikh, 2010). However, there have been many cases of wrong diagnosis and prescribed medications by health facilities in many countries, including South Africa (Lewandowski et al., 2017; Fico et al., 2016). The problems are linked to many factors including analysis of patients' big data (Sacristán \& Dilla, 2015). From a healthcare standpoint, the characteristics of big data are volume, variety, and velocity (Priyanka \& Kulennavar, 2014). The unprecedented types, speed, and sources of patients' big data do sometimes create challenges and limitations in its accessibility, quality, use, and management in providing and receiving healthcare services (Ganjir, Sarkar \& Kumar, 2016; Nativi et al., 2015).

Big data that are for specific purpose and usefulness require harnessing its capabilities, from both technological and human standpoints. Thus, analytics tools are needed to analyse diverse big data types, at velocity, and real-time (Priyanka \& Kulennavar, 2014). However, big data analytics

\section{DOI: 10.4018/JCIT.2021010104}

This article, published as an Open Access article on January 11, 2021 in the gold Open Access journal, Journal of Cases on Information Technology (converted to gold Open Access January 1, 2021), is distributed under the terms of the Creative Commons Attribution License (http://creativecommons.org/licenses/by/4.0/) which permits unrestricted use, distribution, and production in any medium, provided the author of the original work and original publication source are properly credited. 
can be a disruptive phenomenon, from privacy and standardisation perspectives (Bello-Orgaz, Jung $\&$ Camacho, 2016). This is attributed to largeness and complexity of big data, which analytics tools have so far found difficult to address at socio-technical levels (Ularu et al., 2012). In South Africa, this has been a serious challenge for many health facilities (Ruxwana, Herselman \& Conradie, 2010).

There have been gaps in patients' data which impedes progress in the South Africa healthcare environment (Coovadia et al., 2009). Thus, Mgudlwa and Iyamu (2018) suggest that the integration of various datasets is essentially relevant and useful to healthcare service providers. From South Africa viewpoint, Mayosi et al. (2012) argue that good-quality data in a timely manner is always needed due to the rapid changes that happen in the health environment. This is contrast with the on-going improper coordination and management of patients' data, which leads to incorrect diagnoses and treatments (Ruxwana et al., 2010).

Based on the challenges established above, this study attempts to answer the question: What are the factors that influence access, use, and management of healthcare big data in the South African health facilities? In answering this question, it was necessary to examine the actors (personnel and technologies) that are involved, their roles in accessing healthcare big data, and how the activities involving big data are translated or manifested. Thus, moments of translation from actor-network theory (ANT) (Callon, 1986) was selected to guide the analysis. The core tenets of ANT are actor, network, and translation (Latour 2005). Iyamu and Roode (2012) describe ANT as a theory which focuses on the interaction between humans and technology.

This article is structured into seven main sections. The first section introduces the entire article, followed by sections covering review of literature about actor-network theory and big data, respectively. The research methodology is discussed in the fourth section. The fifth and sixth sections present the data analysis and discussion of the results, respectively. The conclusion is drawn in the last section.

\section{ACTOR-NETWORK THEORY}

Actor-network theory (ANT) focuses on how human and nonhuman actors form stable, heterogeneous networks of aligned interests through processes of translations and negotiations (Callon, 1986; Law, 1992). According to Latour (2005), ANT is holistic in its incorporation of humans and non-human into actor-network. This means that human and nonhuman actors have relationship, which ultimately shapes each other (Law, 1992). Despite possible human actors' different understandings and intentions, they are able to associate and influence each other (Latour, 2005). In ANT, translations are the interactions that happen between actors and their many manifestations (Callon, 1986). Translations entails four moments: problematization, interessement, enrolment and mobilisation (Callon, 1986). Accessing, use and management of healthcare big data involve processes of interaction and negotiations between: humans, human and nonhuman, and nonhumans.

Accessing, using and managing patient' big data for healthcare service delivery are stages influenced by various factors, which manifest from translations during interactions between actors. Problematization is to initiate an idea, foster relationships, and allocate and reallocate power between the involved actors (Akrich, 1992). Each or a combination of the stages is a situation that has to happen in order to provide healthcare services. Callon (1986) refers to such situation as Obligatory Passage Point (OPP), which has to occur in order for all the actors to satisfy the interests that have been attributed to them by the focal actor. At the stage of interessement, the focus is to understand how healthcare practitioners became interested in accessing, use and management of patients' big data for healthcare service delivery. Interessement is the set of actions by which an entity attempts to impose and stabilise the identity of other actors in the same network for the cause of problematization (Akrich, Callon \& Latour, 2002).

The third, enrolment stage involves the consolidation of alliances through bargaining and mutual concessions (Law, 1992). This helps to examine and understand various roles in accessing, use and management of patients' big data. Callon (1986) explains that actors accept the roles defined for them 
when enrolling in the network. ANT proposes that enrolling allies creates aligned interests and the translation of their interests must be such that participation will lead to the network's maintenance (Latour, 2005). Enrolment can be seen as a successful outcome of the 'problematization' and the 'interessement' processes. Finally, actor represents the network (Callon, 1986). Some actors are used as (new) initiators. They become delegates or spokespersons for the focal actor. The new network starts to operate in a target-oriented approach to implement the solution proposed.

Actor-work theory (ANT) is sociotechnical theory that focuses on actors, networks, and the relationship and interaction that take place between actors within heterogeneous networks (Latour, 2005). The relationship and interaction between actors passes through translation from the perspective of ANT (Calon, 1986). Many studies have been conducted in the field of ICT and healthcare, where the four moments of translation from the perspective of ANT were employed as a lens in the analysis of the data (Mauthe \& Webb, 2013; Cresswel et al., 2010; Heeks \& Stanforth, 2007). According to Iyamu (2018), ANT is appropriate for gaining better understanding, formulation, and stabilisation of groupings, referred to as networks of data sets, in the analytics of big data.

\section{LITERATURE REVIEW}

Healthcare data includes personal medical records, radiology images, clinical trial data, FDA submissions, human genetics and population (Feldman, Martin \& Skotnes, 2012), which Hansen et al. (2014) classified as big data because of its size, variety and velocity nature. Big data in healthcare challenges relates to its characteristics, which include volume, variety, velocity, and veracity (Acharjya \& Kauser, 2016; Asri et al., 2015). Wang and Krishnan (2014) state that the size of data sets within healthcare affects important aspects, such as storing, processing, and analysing of data. Mancini (2014) explains that these challenges call for new approaches to big data. Peisker and Dalai (2015) are of the view that the integration and analysis of health data can actually address many persistent problems within the healthcare sector.

In addition to size, another description of big data is that it is also unstructured in nature, thus adding to its complexity. According to Gulamhussen et al. (2013), the healthcare sector produces thousands of unlinked data which is classed in multiple categories such as clinical data, claims, pharmaceuticals, medical products, research and development data, patient behaviour, and sentiment data. Based on Priyanka and Kulennavar's (2014) description, big data in healthcare is the result of digitization of healthcare data, which had already accumulated over the years but in paper form. However, generally speaking, the term Big Data is defined as a tool and technique which contains information of value but for that information to be uncovered, innovative integration has to be in place (Sathiyavathi, 2015). This definition leads to the description of healthcare big data. These are large and complex data sets, which cannot be handled with traditional systems and which consists of data such as patient information (Ganjir, Sakar \& Kumar, 2016). Raghupathi and Raghupathi (2014) state that healthcare big data can easily be defined with 4 Vs of big data.

There are points of importance to highlight the issues and challenges that persist in the use of big data. Augustine (2014) points out that the biggest challenge seems to be that big data exists within legacy systems which makes it hard to relate to other data. Furthermore, Archenaa and Anita (2015) suggest that the challenge is no longer just a lack of information but rather lack of information which can lead to better decision making in healthcare. In addition, Chen and Zhang (2014) purport that these challenges may result in big data becoming a gold mine that we cannot extract any value from because we lack the means to explore it. In support of this Kankanhalli et al. (2016) state that challenges in analysing data stem from the variety within healthcare, implying that the data is both structured and unstructured since it appears in various formats and from various sources. The type of data set, whether structured and unstructured, influences disparity especially in developing countries (Ruxwana et al., 2010). 
Evidently, some of the diagnoses within the South African healthcare are caused by disparities in existing data and records of patients (Benatar, 2013). Leon, Schneider and Daviaud (2012) argue that some of the disparities in South African primary health care are influenced by culture and capacity, as well as the poor availability and use of ICT. According to Mayosi et al. (2012), data system in the South African healthcare is a challenge, which affects national distribution of patients information. Mgudlwa and Iyamu (2018) therefore suggest that big data analytics can help to integrate and harness healthcare data for more purposefulness. It is within this context that actor-network theory was selected to examine the interactions that happen among actors, which manifest to factors that influence various stages in gathering, accessing, use and management of patients' big data for healthcare service delivery in South Africa.

\section{RESEARCH METHODOLOGY}

To fulfil the objectives of this study, qualitative research methods were followed. This is mainly because the methods place emphasis on highlighting and explaining human experiences (Chinedu et al., 2014), through which factors that influence access, use, and management of big data can be identified. The case study approach was employed in the design of the research, primarily because it allows investigation of an entity, in a natural setting (Yin, 2017). A healthcare facility, Salem Clinic in Eastern Cape of South Africa was used in the research. Salem Clinic participated in the research for two main reasons: accessibility and it fulfils the criteria needed. Eight facilities were contacted and requested to participate in the research, but declined. The Salem Clinic fulfilled the requirements for a healthcare facility, which was the criteria for this research. The facility attends to over 6000 patients per month.

The semi-structured interview technique was used to collect qualitative data. This is because the technique allows for conversation between interviewer and interviewee, which helps to provide clarifications during the process (Cohen et al., 2013). A total of ten participants were interviewed. This includes doctor (x2); nurse (2); clerk (x1); data capturer (x1); pharmacist (x2); and radiographer(x2). With permission, the interviews were tape recorded and transcribed. Each participant was assigned a name-code: SC_P1 to SC_P10. This was purposeful in order to protect the identities of the participants as well to adhere to ethical considerations of the facility. A format was applied in accessing the data for analysis purposes: Participant, Page number, line number. For example, SC_P1, Pg 1, 102-103.

The four moments of translation are problematization, interessement, enrolment and mobilisation from Actor-Network Theory (ANT) (Callon, 1996) was selected and used as a lens to guide the analysis of the data. The focus was to determine the factors that influence access, use and management of patients' big data for healthcare service delivery in South Africa.

\section{ANALYSIS OF DATA: ANT VIEW}

In the use of ANT, first, the actors that exist in the environment was established. This is followed by understanding the types of networks within the healthcare facility. These help to gain a better understanding of the various roles as well as the relationship and interactions that happened. The moments of translation cover how patients' big data are consciously or unconsciously accessed, used or managed in the process of providing or receiving healthcare services.

\subsection{Actors}

As in the norm, there were different actors, human and non-human within Salem clinic. The health facility consists of many different employees, divided into two main groups, namely, medical and administrative personnel. The human actors were medical and administrative personnel. The nonhuman actors include processes, big data, IS/IT solutions, and medical apparatus. The medical 
employees included doctors, nurses, radiographers, and pharmacists. The other group which were non-medical personnel consists of counsellors and administrative staff. The actors play critical roles in how big data were collected, accumulated, utilized, and managed at the facility.

In Salem Clinic, the data was gathered included voice, text, and images. The voice data was particularly derived from staff interaction with patients through telephonic conversations. Text data were gathered from the administrative and medical part of the facility through notarizes of patient visits and their details, while the medical staff were responsible for writing notes on the reason for visit and other information. The X-Ray machines produce image data, which the medical staff then use for activities such as conducting diagnosis. A radiographer at the facility briefly describes the process as follows:

The result of patient's $x$-ray goes to the doctor, who carries out the review, and confirm the diagnosis. (SC_P6,pg 20:998-999)

Salem Clinic employs different technological artefacts, which included medical apparatus and IS/IT solutions. The medical apparatus were used to examine patients' health condition through diagnoses and X-Rays. While the IS/IT solutions were used for activities such as collection and storage of patients' medical records, interactions, and events. One participant indicates:

There are computers used by the manager, clerks, doctors and the pharmacy (SC_P1, Pg 6: 280-281). There is a certain software used to capture that information, not one software but there is one which integrates all services. It is called District Health Information System (DHIS). (SC_P5, Pg 13: 638-640)

In the process of healthcare service delivery, the employees worked in isolation. Similarly, the apparatus or data were not applied in a vacuum. The human actors operated in groups (networks) as they access and applied various tools (big data and medical apparatus), making the nonhuman actors part of the networks.

\subsection{Networks}

Networks are formed through a linkage of actors with similar interests or qualities as argued by Borgatti and Halgin (2011). At Salem Clinic, there were three main networks, which consisted of healthcare practitioners, IT and administrative personnel. The networks of healthcare practitioners included doctors, counsellors, radiographers, pharmacists, and nurses. Another group of people were the patients. The patients were unconsciously divided into groups based on their health conditions and purpose of visits to the facility.

Despite the use of technology within the facility, there was no designated IT department within the facility. However, there was availability of IT artefacts, which constitute a network of its own. On the administrative side, Salem Clinic employs data capturers and clerical assistants. This group of administrative staff share a common goal which was to capture patient information. One of the administrative staff describes her job role as follows:

We as admin clerks register patients, whether first-time or regular clients. For children below the age of 12 years, we always advise them to bring a clinic card. Thereafter, we create a file, before sending them to the respective medical personnel (SC_P2, Pg 6: 299-303).

The medical and administrative staff both interact with the data using the different sources. Through their different contributions, data is accumulated, processed, and stored. The set of data was used for different purposes within the facility, but the end goal was to enable decision-making. 
The data goes through different stages until it reaches a point of usefulness to the organization and the body that conducts decision-making.

\subsection{Moments of Translation: Problematization}

Like other healthcare service providers, Salem Clinic collects and accumulates data from patients on a daily basis, as patients visit the facility. The accumulation of data begins from two main sources, namely patients' walk-in and via technology devices, which include telephone conversations and email. The data is used to diagnose the health conditions and trace medical conditions and history of the patients. Therefore, it is critical that the patients provide enough and accurate information about themselves. On a patient's visit at Salem Clinic, consultation takes place, which follows two main steps: (1) inquiring whether it is the patient's first visit, or he/she is a returning patient; and (2) a nurse determines the patient's purpose of visit.

Both steps are parts of problematizing a patient's presence at the facility. The patients provide information about themselves based on their knowledge. Many patients sometimes struggle to express themselves or articulate their condition clearly enough for the medical personnel to understand them. At Salem Clinic, there has been cases of a patients presenting inaccurate information about their condition or purpose of visit. This was common among the youths that visit the Salem Clinic. One of the experienced (having served for over ten years) nurses explained as follows:

The information that the patients provide is often influenced by the type of disease they had. Especially the youth, we had cases where a patient had STI, which he was fully aware of, but decide to offer unrelated information because he was shy. (SC_P1, Pg 2: 76-78)

The initial incorrect information that some of the patients provide about themselves was influenced by culture and understanding. Culture may affect a patient's willingness to disclose information, for instance, some male patients do not think that a person of the opposite sex needs to know about their private medical conditions. Furthermore, the patients are not always well educated to understand that medical conditions do not have boundaries of gender affiliation.

Additionally, the patients provide information based on how they are guided or the type of questions that were asked of them by the medical personnel. This is the primary reason that personnel require intensive training as an administrator or first aid personnel to the patients. Another critical aspect is how the administrative and medical personnel gather information from the patients. This include what tools, such as language, automated system, or manual process, are used to gather information from the patients. At Salem Clinic, the majority of the patients were isiXhosa speaking Africans. However, some of the nurses and other personnel were people of other races, such as Coloured. Even though some of the personnel sometimes spoke in isiXhosa, it was never the same, in that there are always cultural differences. One of the nurses shared her experience:

I am not a Xhosa speaking person, even though I do understand a bit of the language. As a result, I'd rather prefer to consult in English language, to avoid complication. (SC_P1, Pg 1:3)

Based on the information that is provided by the patient, medical personnel, from general practitioners to specialists, including nurses, are assigned to carry out further checks and diagnosis. Even though the medical practitioners are assigned, different factors influence their interest in the patients' health conditions.

\subsection{Moments of Translation: Interessement}

For each patient's condition, there were different stakeholders: the patients themselves, patient's relations, support (IT), medical personnel at the Salem Clinic, and the South Africa Department of 
Health (DoH). Each of these stakeholders have interest of consciousness and unconsciousness in patients' health conditions.

Patients visit Salem Clinic with the intention of receiving medical treatment. Their interest stems from their need for healthcare services that the facility offers, in order to better their state of health. The services are offered in different forms, which include referrals to specialists, prescriptions for medication, and actual medical care to patients with less serious conditions. These services are captured and documented by using IS/IT artefacts. The documentation enables follow-up, tracking and tracing of individual patients. Parents or relations' interest was evident in their efforts leading up to, or during, the treatment process, with some acting as patient escorts/porters.

The DoH formulates policies to guide health services in South Africa. Based on some of the policies, technological solutions, such as the District Health Information System (DHIS), Tier.Net, and the Electronic TB Register (ETR.NET) were implemented. One of the medical personnel at Salem facility explains as follows:

A report is compiled monthly and submitted to sub-district level, and escalated to provincial and national levels. Using DHIS, the department is able to identify gaps, in improving performance. (SC_P1, Pg 13: 655-661)

The various interests on patients' care are influenced by different factors, which include care, availability of medications and medical apparatus, availability of qualified medical personnel, and the use of IS/IT artefacts to enable and support the activities. These interests only become materialised, produce care if put to use through participation of the associated and affected actors.

\subsection{Moments of Translation: Enrolment}

In Salem Clinic, participation of stakeholders in the process of patients' care was determined by different factors, which include roles and responsibilities, and rules and regulations that were put in place by the management. The medical and administrative staff of Salem Clinic take part in the process of patient care within the facility through offering their services. As medical staff, doctors within Salem Clinic are available daily to conduct their duty towards the patient by providing medical treatment to them. This starts with consultation, wherein they check the patients' complaints and weigh it against their medical history presented in the folder. Thereafter, a doctor is able to conduct a diagnosis, provide treatment, and advise the patient based on their findings. These activities show participation from this category of medical staff. Individually, these doctors have their roles and responsibilities; however, they are still required to work jointly with other staff within the facility. Consequently, nurses are second order to the doctors.

The different roles and responsibilities of medical staff do not mean that they work in isolation. There is a systematic process that happens with patient care and this tightly links the medical staff of Salem clinic. Following this process, nurses are responsible for sending patients to the pharmacy within the facility to receive their medications. As one participant points out:

In accordance to the process, everyone that has been seen or first-aid examined by the nurses still have to visit the pharmacy. (SC_P1, pg 1: 19-20)

Pharmacists at Salem Clinic were at the end of the patient care process at the facility. However, they were pivotal to the process because medications were administered by them to patients, as per the doctor's or nurses' instruction. Moreover, they were responsible for ensuring that patients receive the correct medications as stated in their prescriptions. As a primary stakeholder, their participation was driven by their job role. Another factor that motivates participation in the pharmacy department 
was auditing that takes place. The DoH ensures that the medications that were administered by the facility pharmacy was recorded. An interviewee states as follows:

The nurses and pharmacists who are responsible for dispensing medications were also obligated to record what medications has been administered to patients. (SC_P5, pg 18:869-870)

In addition, the administrative personnel of Salem Clinic were responsible for ensuring that the medical staff were able to conduct these activities in a systematic manner. Patients follow a particular process from the moment that they enter the facility. Their responsibilities were centred around the medical unit, as they have to guide the patients through the different activities that occur while receiving treatment. Their participation in patient care was measured by how smooth the process was, starting from registration to the moment they receive medication. However, the process was challenged, in that some patients were not able to provide sufficient documentation and information, for efficient service.

The other group of stakeholders, DoH, actively contributes to the activities and processes of healthcare in the country. Some of the key areas of participation; training of nurses and health workers; provision of medical equipment; formulation of policies that govern for both private and public health practice; and formulation of policies that govern health professionals. Like any other organization, the availability of equipment was valuable to Salem Clinic. With proper equipment, medical and administration staff are able to conduct their duties with ease. This also contributes to the quality of care, which was influenced by existing patients' data.

However, monitoring and evaluation become challenging, especially to those who were responsible for ensuring that they were carried out correctly. This includes data capturers of Salem clinic. In their participation with regards to providing care to patients, they have to ensure that the correct information was captured on the systems, which forms the types of patients' data. The patients of Salem Clinic, both chronic and acute, have had to adapt to the processes imposed on them by the facility. Due to their need for medical care, they were required to follow these processes and to make use of the solutions introduced by the facility, specifically the chronic patients, who were registered under programs such as Tier.NET and ETR.net. Through these processes, big data were collected and stored. An interview provides an example of the type of information patients would have to give out:

Programs such as Tier.Net, it's all about the patients. You capture their names, addresses, HIV status, ARV treatment and how well controlled they were. (SC_P5, Pg 17: 679:681)

There were different stakeholders enrolled in the process of patient care at Salem clinic. The medical staff and administrative staff contribute through providing a service, while the DoH enables this through providing support, both financially and with technological resources. The patients of Salem Clinic stand to gain medical assistance; therefore, they were obligated to comply with the processes put in place by the facility. Patients' participation did not guarantee success and functionality of these processes and systems of Salem Clinic. Therefore, for them to be considered successful, mobilisation needs to take place.

\subsection{Moments of Translation: Mobilisation}

Salem Clinic encounters multiple spokespersons at various stages of each patient' care duration. Some of these spokespersons were representatives of the facility, while others were self-appointed. The spokespersons responsible for mobilising other actors into participating in activities surrounding patient health were both internal and external to the organization. Internally, the elected representatives included management. As the decision makers, they can enforce participation from the different departments within Salem Clinic. A participant states the following: 
Everything is dependent on management. This is because, as the verification committee we can only do so much. We are restricted in many areas. (SC_P5, Pg.16: 787-789)

This may affect the facility both positively and negatively. From a positive perspective, a single point of power of authority regulates the operation of the facility. This happens in two ways: (1) employees know their reporting lines; and (2) the DoH is aware of structure and accountability of the facility. However, having a single point of power can also negatively affect productivity within the organisation. Decisions regarding the facility could only be undertaken and implemented by the management. Therefore, in its absence, certain decisions and actions cannot be made, which can result in delays of the patient care process. Furthermore, the DoH that governs the facility places all responsibility upon this section of Salem Clinic. This means that accountability was not shared across the organisation and this could negatively impact those who constitute management in the facility.

Like any other health facility, Salem clinic encounters emergency situations. In such cases, doctors were the representative of the patients in need of urgent medical care. As a smaller scale healthcare facility, there were cases they had to escalate to bigger facilities that were equipped with more tools and resources. Also, the facility encounters cases of patients who were unable to communicate their problem as they wait to be attended. This requires another party to act as proxy to the medical staff. The facility refers to those people as patient escorts. These can be relatives or friends to the patient. Views from some medical personnel are as follows:

If our doctors feel it's a case that needs emergency medical attention or a theatre, then it is referred to nearby facility, a hospital. (SC_P1, Pg.6: 290-292)

An escort was given the responsibility to articulate the patient's case as best as they can for them to get treated. This requires them to know the patient well so that they can give information to the medical practitioner. This was critical, especially in the absence of a patient file. With no view of the patient's history, doctors or nurses at Salem Clinic were unable to give prognosis and the treatment process was delayed. This becomes even more challenging when a patient was brought into the facility by someone who has no knowledge of them and was just there to assist. A doctor in the facility states:

It was often difficult to obtain information from some patients during an emergency situation. It gets more difficult when a stranger brings a patient who desperately needed medical attention, because no one can offer information about the patient. (SC_P4, Pg.12:562-563)

Clearly, the level of familiarity between the patients and their representative is crucial in the treatment process. Failure to thoroughly communicate the case endangers the patients as this requires doctors to treat patients without thorough background knowledge. Furthermore, this contributes to misdiagnosis and dispensing of wrong medication. The DoH also had representatives that visit Salem Clinic to ensure that the resources they provide were utilised efficiently. These resources included the medication they dispense to the organisation. This was done through the evaluation of data collected by the facility.

Mobilisation of stakeholders could be carried out by anyone. However, due to the sensitive nature of the health environment in South Africa, there were restrictions. Thus, only persons with legal authority could speak on behalf of the patient of the health facility, Salem Clinic. This had both negative and positive influence in the activities of the Clinic. For example, there was no firm solution because some patients do not insert their correct addresses on their folders, leading to the facility being unable to track them, in that it could not be interrogated by unauthorised persons. 


\section{RESULTS AND DISCUSSION}

From the above analysis, there were five main factors that influence access, use and management of big data, therefore, determine the selection of analytics, for the analysis of healthcare data. The factors are: common health facility requirements, structure of the big data, integration of healthcare systems, availability of skilled personnel, and the availability of patients' data sets. These factors are all interconnected in one way or another, as shown in Figure 1.

Figure 1. Health facility influencing factors

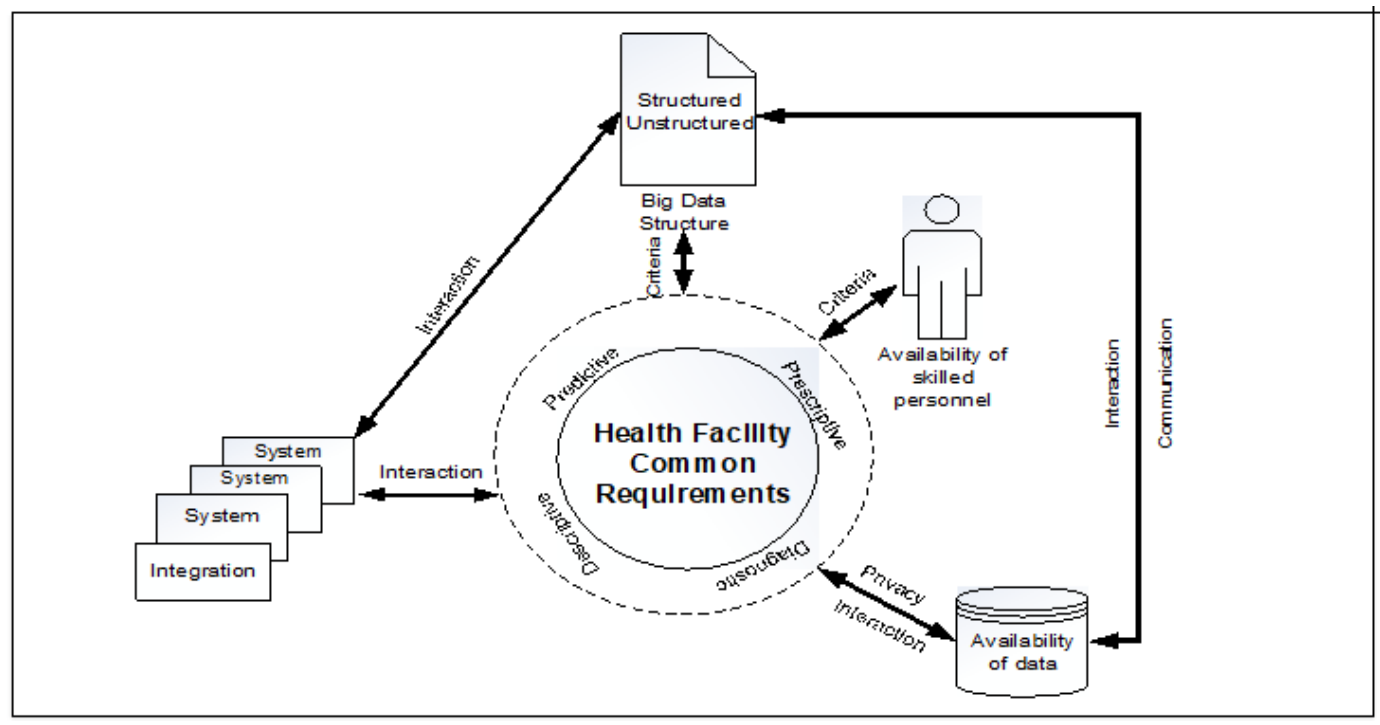

\subsection{The Source and Structure of the Big Data}

Salem Clinic has been in existence for many years and they have evolved in their way of handling data. However, they still use traditional methods in conjunction with technology and both contribute equally to gathering and management of their big data. This has resulted in structured and unstructured data. The structured data is sourced from their traditional filing systems. Their files contain textual data of the patient and these are all placed in their suitable fields. These fields contain data such as the individual's demographics and their reasons for visit. The technological tools used to capture this data were centred around these traditional systems. They were similar, but one was manual while the other was computerised; however, both generate structured data.

On the subject of technology, the facility uses different tools to carry out the patient care process. This includes computers, telephones, and x-ray machines. These tools generate unstructured data which comprises of voice, image, and video data. These sets of data were equally as important as structured, but it often goes unattended to. This was attributed to the facility's data tools giving no consideration to them. This impacts Salem Clinic's data analytics, in the sense that there is a fundamental part of data that was not being included. This brings to question the completeness of data and its impact on the results that were yielded when it's analysed.

\subsection{The Availability of Suitable Big Data Manipulation Tools}

At Salem Clinic there were systems (tools), which were used to gather and store patients' data. These systems were provided by the South African Department of Health (DoH). The systems included 
Tier.Net, ETR.Net, and the District Health Information System (DHIS). These tools were designed mainly to store patients' data. However, the tools differ in terms of their criteria and requirements that were needed in deploying them.

Tier.Net was specifically designed to store data of patients who have been diagnosed with HIV/ AIDS. This was due to the high influx of HIV/AIDS patients in facilities. The lack of infrastructure led to the facility being unable to handle patient data using only a paper-based system. However, before deploying the system, Salem Clinic had to fulfil certain criteria. These criteria included serving more than 600 patients and being unable to accommodate patient data using only a paper-based filing system. Considering that this was a technological solution, the facility had to migrate to using computers as a requirement.

The ETR.Net is a smaller system created specifically for patients who have been diagnosed with $\mathrm{TB}$, and needed treatment. The system was designed to capture patient data from the diagnosis stage until treatment was successful. Since this is not a lifelong disease, specifications and requirements stated that a patient may only exist on the system for six months, as this was the TB treatment period. Thereafter, they would be removed from the system unless they relapse. From the facility's perspective, it was meant to improve data coordination with regards to TB patients. Therefore, the only criteria were facilities who diagnose and treat patients diagnosed with TB.

The DHIS was designed to store data for all patients who visit the facility. The purpose of this system was to collect statistical data of the facility's therefore, the criteria was location based. The system encompasses data of patients who reside in that catchment area. Therefore, the only requirement was that the patient seeks treatment from the facility. The same patient can also exist in the facility database (DHIS). This brings about issues of duplication and this has not been fully explored by the facility at the time of this study. These issues relate to lack of integration between the databases. Another issue was failure in establishing common requirements with regards to data analytics. The facility has not explicitly stated what they would like to gain from the data.

\subsection{The Availability of Standardized Big Data Interpretation Criteria}

The existence of big data is futile to the organisation unless they know what they seek to gain from the data. The facility has tools at their disposal; however, they have not considered the potential of their data. There were no standardized requirements stated with regards to big data and how it can improve the quality of healthcare in the facility. There were various options available that could be of benefit to their cause. However, the choice was dependent on the facility's common requirements, which they have not yet established at the time of this study. These options include (1) prescriptive; (2) predictive; (3) diagnostic; and (4) descriptive big data analytics.

As a healthcare facility, Salem Clinic lacks the necessary tools to determine which illnesses mostly affect patients that visit the clinic. Therefore, they have no knowledge on what areas to prioritise in an attempt to reduce the number of patients visiting the clinic with the same problem. There were only two areas of focus in the facility, namely HIV/AIDS and Tuberculosis. These diseases were only prioritised under the DoH's command. However, with the help of prescriptive analytics, the facility could find out what health issues are prevalent in the community. These would be specific to their patients and they would know which areas to mostly focus on.

Additionally, Salem Clinic was situated in an area of Eastern Cape of South Africa that is prone to health outbreaks. This is due to the living conditions of people and lifestyle. However, the facility has no foresight on these outbreaks due to insufficient use of their big data. With the use of predictive analytics, they could view patterns based on past occurrences. These could give them a view of what could most likely happen in the future with regards to patient treatment. Similarly, diagnostic analytics would be highly beneficial to the facility, mainly because it serves a big part of their purpose. The facility would be able to uncover the reasons behind occurrences; thus, enabling them to prevent its repetition. 
Mining the data through descriptive analytics would help the facility gain knowledge on rampant issues affecting patients. Further investigation into these problems would help in improving the patient care process and standard of the facility. However, these tools can only be of use once the facility uncovers its purpose for big data. That would help in determining which data analytics tools suit the facility's goals, and this requires an explicit communication of their requirements. This brings about the issue of integration within the facility. The type of data analytics tool to use is most likely to be determined by the medical personnel of the facility. The medical personnel know what issues they face due to lack of foresight and insight. Therefore, they should be working jointly with those who handle data in order to find a data analytics solution best suited for the facility. However, that is not possible unless integration of different units in the facility takes place.

\subsection{The Degree of Big Data Integration of the In- House Healthcare Information Systems}

Several issues affect Salem Clinic. These were rooted in the dispersion of resources meant to serve patients visiting the clinic. This includes the staff and technological resources of the facility. Salem Clinic lacks a properly coordinated patient care system. There were five different departments, all operating under the same facility but somehow, they were still disintegrated. This was from the perspective of operations within the facility and the process that data goes through.

The facility has five different departments and they all have the same purpose of serving the patient. In all these departments, a report has to be written on the patient's file and it has to indicate what was conducted and the next step in treatment. In that process, the data was prone to error because many people were involved in carrying it out. By the time all data has been collected, it was difficult to trace where errors occurred.

These errors decrease the quality of data being collected in the facility. Thus, leading to analysis being conducted on data that were not up to par. This could be avoided if integration was in place because data would be collected and updated in real time. The issue also relates to level of knowledge around data analytics in the facility. These problems cannot be raised, because no skilled personnel were available to provide input regarding data, its importance, and how it can be analysed.

\subsection{The Availability of Medical Personnel Skilled in Big Data}

The facility, Salem Clinic, has been in operation for a decade. Even though the health clinic has been in operation for many years, it continues to use the same manual systems to capture and store patients' data. This was irrespective of the fact that the DoH has provided technology solutions (systems) to health facilities in the country, including Salem Clinic. The non-use of the technologies was attributed to lack of knowledge and know-how, which results to unavailability of skilled personnel.

The facility was also lacking in terms of skilled personnel to handle the data that accumulates daily in the facility. This brings the facility's management into question as they were responsible for decision making in the facility. Management has failed to address skills acquisition for data analytics. This includes education, training, and retention of staff who specialise in data analytics. This has led to the neglect of data analytics, which would help in improving the healthcare standard of Salem Clinic.

\subsection{The Availability of Relevant Big Data Sets}

At Salem Clinic, patients' data were accessed by different personnel. This includes clerks, nurses, doctors, radiographers, pharmacists, and data capturers. As a result, patients' data were split into sets in accordance to area of specialisation and responsibilities. For example, the clerk can only have access to patient data which relates to administration, such as contact details and bio-data. This makes certain sets of data unavailable to some personnel. The unavailability of the entire data makes it difficult or challenging for the analytics approach, which somehow affects the completeness of results that were obtained from big data analysis. However, at the same time, it must be noted that the unavailability of complete data is often justified from privacy and security perspectives. 
The availability of patients' data requires policy and regulation in order to manage and maintain the privacy and security. Privacy was a valued element in patient information. It creates a sense of trust between the patient and medical caregiver. This was based on the sensitivity of information shared during the treatment process. It ensures that a patient knows that any information they divulge was kept between them and the person treating them. However, this affects the completeness of data based on the fact that some information regarding the patient is only limited to certain people within the facility. This brings about the aspect of security as well. Patient information requires a high level of security. The facility has to ensure that information shared by a patient was not accessible to anyone unless consent was given by the patient. This requires regulation, and was done by limiting access only to those who are treating the patient. This was to avoid cases, such as patient data being used for malice or a data leak that could have legal consequences. Therefore, the facility can only make certain sets of data available for consumption.

There were other issues that contribute to incomplete data, such as missing or incomplete patients' medical reports. In addition, the facility lets patients keep their own files and this leads to damage of patient files and loss of information. This also affects data analytics of the facility negatively as they were now required to conduct analysis on incomplete data. These issues stem from a lack of integration within the facility. Data was only prioritised by one part of the facility, namely the data capturers, whereas, the different departments should be working in conjunction as they all contribute to big data. The facility lacks an integrated data process from the beginning of patient treatment until the last stage.

\section{CONCLUSION}

This study highlights the factors that influence access, use and management of patients' big data for healthcare service delivery. The factors directly or indirectly impact the quality of healthcare services being provided within South African healthcare facilities. The factors exist because many of the facilities are often challenged with analysis of their patients' big data. Thus, the study can be of benefit to South African health practitioners primarily because some of the factors can influence and how they manifest in the activities and process of healthcare services.

The contribution of this study extends further in two ways: theoretically and methodologically. Theoretically, this study adds to the existing body of knowledge within IS and Healthcare fields. Methodologically, the use of ANT as a guide through analysis provides a fresh perspective to analysing IS related phenomena. Further studies can also be conducted on this research, through the application of different theories that are commonly used in social science. 


\section{REFERENCES}

Acharjya, D. P., \& Kauser Ahmed, P. (2016). A Survey on Big Data Analytics: Challenges, Open Research Issues and Tools. International Journal of Advanced Computer Science and Applications, 7(2), 511-518.

Akrich, M. (1992). The de-scription of technical objects. In Shaping Technology/Building Society: Studies in Sociotechnical Change. Cambridge, MA: the MIT Press.

Akrich, M., Callon, M., Latour, B., \& Monaghan, A. (2002). The key to success in innovation part I: The art of interessement. International Journal of Innovation Management, 6(02), 187-206. doi:10.1142/ S1363919602000550

Archenaa, J., \& Mary Anita, E. A. (2015). A survey of big data analytics in healthcare and government. Procedia Computer Science, 50(1), 408-413. doi:10.1016/j.procs.2015.04.021

Augustine, D. P. (2014). Leveraging big data analytics and hadoop in developing India's healthcare services. International Journal of Computers and Applications, 89(16), 44-50. doi:10.5120/15719-4622

Bates, D. W., Saria, S., Ohno-Machado, L., Shah, A., \& Escobar, G. (2014). Big data in healthcare: Using analytics to identify and manage high-risk and high-cost patients. Health Affairs, 33(7), 1123-1131. doi:10.1377/ hlthaff.2014.0041 PMID:25006137

Bello-Orgaz, G., Jung, J. J., \& Camacho, D. (2016). Social big data: Recent achievements and new challenges. Information Fusion, 28, 45-59. doi:10.1016/j.inffus.2015.08.005 PMID:32288689

Benatar, S. (2013). The challenges of health disparities in South Africa. SAMJ: South African Medical Journal, 103(3), 154-155. doi:10.7196/SAMJ.6622 PMID:23472690

Callon, M. (1986). Some elements of a sociology of translation: domestication of the scallops and the fishermen of St Brieuc Bay. In J. Law (Ed.), Power, Action \& Belief: A New Sociology of Knowledge? (pp. 196-229). Routledge.

Chandarana, P., \& Vijayalakshmi, M. (2014). Big Data analytics frameworks. 2014 International Conference on Circuits, Systems, Communication and Information Technology Applications (CSCITA), 430-434. doi:10.1109/ CSCITA.2014.6839299

Chawla, N. V., \& Davis, D. A. (2013). Bringing big data to personalized healthcare: A patient- centered framework. Journal of General Internal Medicine, 28(S3, Suppl.3), 660-665. doi:10.1007/s11606-013-2455-8 PMID:23797912

Chen, C. P., \& Zhang, C. Y. (2014). Data-intensive applications, challenges, techniques and technologies: A survey on Big Data. Information Sciences, 275, 314-347. doi:10.1016/j.ins.2014.01.015

Chinedu Eze, S., Duan, Y., \& Chen, H. (2014). Examining emerging ICT's adoption in SMEs from a dynamic process approach. Information Technology \& People, 27(1), 63-82. doi:10.1108/ITP-03-2013-0044

Cohen, L., Manion, L., \& Morrison, K. (2013). Research methods in education. Routledge. doi: $10.4324 / 9780203720967$

Coovadia, H., Jewkes, R., Barron, P., Sanders, D., \& McIntyre, D. (2009). The health and health system of South Africa: Historical roots of current public health challenges. Lancet, 374(9692), 817-834. doi:10.1016/ S0140-6736(09)60951-X PMID:19709728

Cresswell, K. M., Worth, A., \& Sheikh, A. (2010). Actor-Network Theory and its role in understanding the implementation of information technology developments in healthcare. BMC Medical Informatics and Decision Making, 10(1), 67-78. doi:10.1186/1472-6947-10-67 PMID:21040575

Dwiartama, A., \& Rosin, C. (2014). Exploring agency beyond humans: The compatibility of Actor-Network Theory (ANT) and resilience thinking. Ecology and Society, 19(3), 28-38. doi:10.5751/ES-06805-190328

Esposito, C., Ficco, M., Palmieri, F., \& Castiglione, A. (2015). A knowledge-based platform for Big Data analytics based on publish/subscribe services and stream processing. Knowledge-Based Systems, 79, 3-17. doi:10.1016/j.knosys.2014.05.003

Feldman, B., Martin, E.M. \& Skotnes, T. (2012). Big Data in Healthcare - hype and hope. Dr. Bonnie 360 degree (Business Development for Digital Health), 2013(1), 122-125. 
Fico, G., Fioravanti, A., Arredondo, M. T., Gorman, J., Diazzi, C., Arcuri, G., Conti, C., \& Pirini, G. (2016). Integration of Personalized Healthcare Pathways in an ICT Platform for Diabetes Management: A SmallScale Exploratory Study. IEEE Journal of Biomedical and Health Informatics, 20(1), 29-38. doi:10.1109/ JBHI.2014.2367863 PMID:25389246

Ganjir, V., Sarkar, B. K., \& Kumar, R. R. (2016). Big data analytics for healthcare. International Journal of Research in Engineering. Technology and Science, 6, 1-6.

Giambrone, G. P., Hemmings, H. C., Sturm, M., \& Fleischut, P. M. (2015). Information technology innovation: The power and perils of big data. British Journal of Anaesthesia, 115(3), 339-342. doi:10.1093/bja/aev154 PMID:26034021

Gulamhussen, A., Hirt, R., Ruckebier, M., Orban de Xivry, J., Marcerou, G., \& Melis, J. (2013, March). Big data in healthcare: What options are there to put patients in control of their data. In Proceedings of the EIT Foundation Annual Innovation Forum (Vol. 26). Academic Press.

Hansen, M. M., Miron-Shatz, T., Lau, A. Y. S., \& Paton, C. (2014). Big data in science and healthcare: A review of recent literature and perspectives. Yearbook of Medical Informatics, 23(01), 21-26. doi:10.15265/IY-20140004 PMID:25123717

Heeks, R., \& Stanforth, C. (2007). Understanding e-Government project trajectories from an actor-network perspective. European Journal of Information Systems, 16(2), 165-177. doi:10.1057/palgrave.ejis.3000676

Iyamu, T. (2018). A multilevel approach to big data analysis using analytic tools and actor network theory. South African Journal of Information Management, 20(1), 1-9. doi:10.4102/sajim.v20i1.914

Iyamu, T., \& Roode, D. (2012). The use of structuration theory and actor network theory for analysis: a Case study of a financial institution in South Africa. In Social Influences on Information and Communication Technology Innovations (pp. 1-19). IGI Global. doi:10.4018/978-1-4666-1559-5.ch001

Jagadish, H. V., Gehrke, J., Labrinidis, A., Papakonstantinou, Y., Patel, J. M., Ramakrishnan, R., \& Shahabi, C. (2014). Big data and its technical challenges. Communications of the ACM, 57(7), 86-94. doi:10.1145/2611567

Kambatla, K., Kollias, G., Kumar, V., \& Grama, A. (2014). Trends in big data analytics. Journal of Parallel and Distributed Computing, 74(7), 2561-2573. doi:10.1016/j.jpdc.2014.01.003

Kankanhalli, A., Hahn, J., Tan, S., \& Gao, G. (2016). Big data and analytics in healthcare: Introduction to the special section. Information Systems Frontiers, 18(2), 233-235. doi:10.1007/s10796-016-9641-2

Kuo, M. H., Chrimes, D., Moa, B., \& Hu, W. (2015). Design and construction of a big data analytics framework for health applications. In Smart City/SocialCom/SustainCom (SmartCity), IEEE International Conference on (pp. 631-636). IEEE. doi:10.1109/SmartCity.2015.140

Latour, B. (2005). Reassembling the social: An introduction to actor-network-theory. Oxford University press.

Law, J. (1992). Notes on the theory of the actor-network: Ordering, strategy, and heterogeneity. Systems Practice, 5(4), 379-393. doi:10.1007/BF01059830

Leon, N., Schneider, H., \& Daviaud, E. (2012). Applying a framework for assessing the health system challenges to scaling up mHealth in South Africa. BMC Medical Informatics and Decision Making, 12(1), $123-135$. doi:10.1186/1472-6947-12-123 PMID:23126370

Lewandowski, L. B., Watt, M. H., Schanberg, L. E., Thielman, N. M., \& Scott, C. (2017). Missed opportunities for timely diagnosis of pediatric lupus in South Africa: A qualitative study. Pediatric Rheumatology, 15(1), 14-23. doi:10.1186/s12969-017-0144-6 PMID:28231857

Mancini, M. (2014). Exploiting big data for improving healthcare services. Journal of e-Learning and Knowledge Society, 10(2), 23-33.

Mauthe, B., \& Webb, T. E. 2013. In the Multiverse What Is Real? Luhmann, Complexity and ANT. In Luhmann Observed. London: Palgrave Macmillan UK.

Mayosi, B. M., Lawn, J. E., Van Niekerk, A., Bradshaw, D., Karim, S. S. A., \& Coovadia, H. M. (2012). Health in South Africa: Changes and challenges since 2009. Lancet, 380(9858), 2029-2043. doi:10.1016/S01406736(12)61814-5 PMID:23201214 
Mgudlwa, S., \& Iyamu, T. (2018). Integration of social media with healthcare big data for improved service delivery. South African Journal of Information Management, 20(1), 1-8. doi:10.4102/sajim.v20i1.894

Moore, K. D., Evestone, K., \& Coddington, D. C. (2013). the big deal about big data. Healthcare Financial Management, 67(8), 60-68. PMID:23957187

Nativi, S., Mazzetti, P., Santoro, M., Papeschi, F., Craglia, M., \& Ochiai, O. (2015). Big data challenges in building the global earth observation system of systems. Environmental Modelling \& Software, 68, 1-26. doi:10.1016/j.envsoft.2015.01.017

Nepal, S., Ranjan, R., \& Choo, K. K. R. (2015). Trustworthy processing of healthcare big data in hybrid clouds. IEEE Cloud Computing, 2(2), 78-84. doi:10.1109/MCC.2015.36

Ojha, M., \& Mathur, K. (2016). Proposed application of big data analytics in healthcare at Maharaja Yeshwantrao Hospital. In Big Data and Smart City (ICBDSC), 20163 rd MEC International Conference on (pp. 1-7). Muscat, Oman: IEEE. doi:10.1109/ICBDSC.2016.7460340

Panahiazar, M., Taslimitehrani, V., Jadhav, A., \& Pathak, J. (2014). Empowering personalized medicine with big data and semantic web technology: promises, challenges, and use cases. In Big Data (Big Data), 2014 IEEE International Conference on (pp. 790-795) IEEE. doi:10.1109/BigData.2014.7004307

Peisker, A., \& Dalai, S. (2015). Data analytics for rural development. Indian Journal of Science and Technology, 8(S4), 50-60. doi:10.17485/ijst/2015/v8iS4/61494

Priyanka, K., \& Kulennavar, N. (2014). A survey on big data analytics in health care. International Journal of Computer Science and Information Technologies, 5(4), 5865-5868.

Raghupathi, W., \& Raghupathi, V. (2014). Big data analytics in healthcare: Promise and potential. Health Information Science and Systems, 2(1), 1-10. doi:10.1186/2047-2501-2-3 PMID:25825667

Ruxwana, N. L., Herselman, M. E., \& Conradie, D. P. (2010). ICT applications as e-health solutions in rural healthcare in the Eastern Cape Province of South Africa. The HIM Journal, 39(1), 17-29. doi:10.1177/183335831003900104 PMID:20335646

Sacristán, J. A., \& Dilla, T. (2015). No big data without small data: Learning health care systems begin and end with the individual patient. Journal of Evaluation in Clinical Practice, 21(6), 1014-1017. doi:10.1111/ jep.12350 PMID:25832820

Sathiyavathi, R. (2015). A survey: Big data analytics on healthcare system. Contemporary Engineering Sciences, 8(3), 121-125. doi:10.12988/ces.2015.412255

Scotland, J. (2012). Exploring the philosophical underpinnings of research: Relating ontology and epistemology to the methodology and methods of the scientific, interpretive, and critical research paradigms. English Language Teaching, 5(9), 9-16. doi:10.5539/elt.v5n9p9

Shah, T., Rabhi, F., \& Ray, P. (2015). Investigating an ontology-based approach for Big Data analysis of interdependent medical and oral health conditions. Cluster Computing, 18(1), 351-367. doi:10.1007/s10586-0140406-8

Tresp, V., Overhage, J. M., Bundschus, M., Rabizadeh, S., Fasching, P. A., \& Yu, S. (2016). Going digital: A survey on digitalization and large-scale data analytics in healthcare. Proceedings of the IEEE, 104(11), 2180-2206. doi:10.1109/JPROC.2016.2615052

Tsang, E. W. (2014). Case studies and generalization in information systems research: A critical realist perspective. The Journal of Strategic Information Systems, 23(2), 174-186. doi:10.1016/j.jsis.2013.09.002

Ularu, E. G., Puican, F. C., Apostu, A., \& Velicanu, M. (2012). Perspectives on big data and big data analytics. Database Systems Journal, 3(4), 3-14.

Wang, W., \& Krishnan, E. (2014). Big data and clinicians: A review on the state of the science. JMIR Medical Informatics, 2(1), e1. doi:10.2196/medinform.2913 PMID:25600256

Yin, R. K. (2017). Case study research and applications: Design and methods. Sage publications. 
Tiko lyamu is a Research Professor at the Faculty of Informatics and Design, Cape Peninsula University of Technology (CPUT), Cape Town, South Africa. He was previously with Tshwane University of Technology, South Africa, and Namibia University of Science and Technology, Windhoek, Namibia. Iyamu served as a Professor Extraordinaire at the Department of Computer Science, University of the Western Cape, South Africa. He was a visiting professor at the Flensburg University of Applied Sciences, Germany. Professor lyamu's areas of focus include enterprise architecture, health informatics, big data analytics, and IT strategy. He has published over 120 research articles in journals, books, and book chapters. Prior to joining academic, Professor lyamu held several positions in both Public and Private Institutions in South Africa. He was Systems' Analyst at Nedcor Investment Bank, and Information Technologist at Metropolitan, an insurance company. Iyamu was the Chief Architect at the City of Cape Town; and IT Architect at Old Mutual. He was also at MWeb, a Telecommunication company, as Head of IT Architecture \& Governance.

Sibulela Mgudlwa holds a Masters' degree in Information Technology from the Cape Peninsula University of Technology, Cape Town, South Africa. Her areas of focus include health informatics and social media. She has authored several research articles in both international and local journals. 